\section{Commentary: If you don't measure it, you can't improve it}

\author{
Bobby Yanagawa, $\mathrm{MD}, \mathrm{PhD},{ }^{\mathrm{a}}$ \\ Maral Ouzounian, $\mathrm{MD}, \mathrm{PhD},{ }^{\mathrm{b}}$ and \\ Tsuyoshi Kaneko, MD
}

Krebs and colleagues ${ }^{1}$ used the cumulative sum (CUSUM) technique to track the progress of 19 residents performing 3937 Society of Thoracic Surgeons Predicted Risk of Mortality cases. Residents experienced a slight increase in complications, followed by better-than-expected outcomes as they increased their surgical experience. We applaud the authors for their efforts to add much-needed data to surgical education, a process that has made little progress from the original apprenticeship model. Can this model be applied widely as an adjunct to resident training?

CUSUM was first developed by Page ${ }^{2}$ in 1954 as a statistical tool to detect deviations from the mean. It has been applied to surveillance in manufacturing, food, service industries, and health care. CUSUM curves have recently been used to document the learning curve for high-end procedures such as complex aortic repair, the Ross procedure, and robotic minimally invasive direct coronary artery bypass. $^{3-5}$

This paper provides several important insights. The question of how many cases are needed to achieve and sustain competence is answered. The rate of complications is greater than expected until about 140 cases. Then, after 200 cases, complications are lower than expected. This is contrary to the recent report by Shah and colleagues, ${ }^{6}$ who have debunked the "July effect" in cardiac surgery and showed that outcomes were similar during the first quartile in teaching hospitals. Another important finding is that residents did improve over time

\footnotetext{
From the adDivision of Cardiac Surgery, St Michael's Hospital and 'Division of Cardiac Surgery, Toronto General Hospital, University of Toronto, Toronto, Ontario, Canada; and ${ }^{\mathrm{C}}$ Division of Cardiac Surgery, Brigham and Women's Hospital, Boston, Mass.

Disclosures: Authors have nothing to disclose with regard to commercial support.

Received for publication Oct 6, 2019; accepted for publication Oct 7, 2019; available ahead of print Dec 6, 2019

Address for reprints: Bobby Yanagawa, MD, PhD, Division of Cardiac Surgery, St. Michael's Hospital, 30 Bond St, 8th Floor, Bond Wing, Toronto, ON M5B 1W8, Canada (E-mail: yanagawab@smh.ca).

J Thorac Cardiovasc Surg 2020;160:469-70

$0022-5223 / \$ 36.00$

Copyright (c) 2019 by The American Association for Thoracic Surgery

https://doi.org/10.1016/j.jtcvs.2019.10.121
}

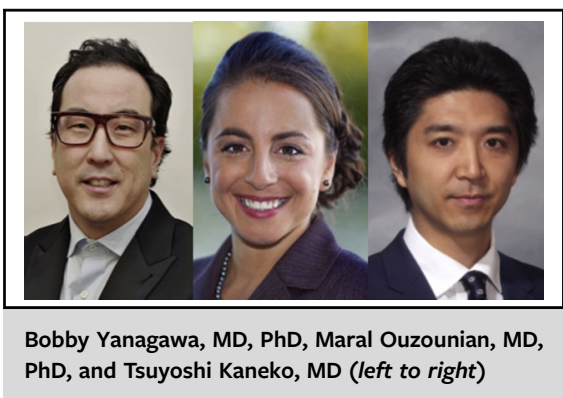

CENTRAL MESSAGE

Cumulative sum, or CUSUM

curves, a method to continu-

ously detect deviations from the

mean, can be used as an adjunct

to monitor resident perfor-

mance in surgical training.

but that few residents crossed the line from greater to lower observed-expected complications. The 2 residents that crossed the upper "alert boundary" ended under this line but remained in the greater observed-expected complication region. In other words, we all have an inherent limit to our abilities, but with adequate training and mentorship, residents can improve and achieve good, safe outcomes.

This study has several limitations: The "alert boundary" is arbitrary, risk adjustment is imperfect, the definition of "primary operator" can vary, the case-mix is limited, and there is no account for the staff surgeon or the team. ${ }^{7}$ The complications reported were chosen as they have validated Society of Thoracic Surgeons risk adjustment models but they may not be directly related to technical misadventures in the operating room. For instance, the major contributors to stroke are aortic manipulation and postoperative atrial fibrillation. The first may be technical, but the second is not. As such, this is a rather narrow tool to measure resident performance. In this model, the occurrence of a negative signal should prompt an investigation but does not necessarily imply deterioration in performance. Also, residents were compared with a "reference" resident and the results would therefore be altered based on the composition of the group. Despite all this, we welcome efforts to bring meaningful and objective data to resident surgical training.

What we need is a real-time, early detection system. To do this, we would need to identify not just "major" 
complications but so-called "minor" complications-paravalvular leak or mitral repair failure requiring a second pump run, graft failure, left internal thoracic artery injury and abandonment, re-exploration for bleeding, off-midline sternotomy, etc. These events are not routinely collected but should be included as part of the residents' operative logs.

The role of the surgical mentor is still front and center in cardiac surgical education and patient safety. As a rule, surgeons should not let a resident do anything in which they can't get them out. Attending surgeons in training programs are still primarily responsible for identifying and correcting technical errors made by residents and to raise a red flag if such errors are made repeatedly and not corrected. However, surgeons may have incomplete memories or bias from the snapshot of resident performance when the exposure is limited. Thus, CUSUM curves can act as an adjunct to offer a complete but 30,000-foot view of resident performance.

In this current era of evidence-based practice, surgical education remains remarkably unscientific. CUSUM analysis can be used to allow residents to know that they are meeting the expectations and to identify early signs of nonadvancement and trigger focused corrective action. The system may be imperfect, but efforts to improve trainee skills and outcomes must begin with more sophisticated measurement tools.

\section{References}

1. Krebs ED, Chancellor WZ, Hawkins RB, Beller JP, Mehaffey JH, Teman NR, et al Objective measure of learning curves for trainees in cardiac surgery via cumulative sum failure (Cusum) analysis. J Thorac Cardiovasc Surg. 2020;160: 460-6.e1.

2. Page ES. Continuous inspection schemes. Biometrika. 1954;41:100-15.

3. Bouhout I, Ghoneim A, Poirier N, Cartier R, Demers P, Perrault LP, et al. Impact of the learning curve on early outcomes following the Ross procedure. Can J Cardiol. 2017;33:493-500.

4. Holzhey DM, Jacobs S, Walther T, Mochalski M, Mohr FW, Falk V. Cumulative sum failure analysis for eight surgeons performing minimally invasive direct coronary artery bypass. J Thorac Cardiovasc Surg. 2007; 134:663-9.

5. Mazine A, Stevens LM, Ghoneim A, Chung J, Ouzounian M, Dagenais F, et al. Developing skills for thoracic aortic surgery with hypothermic circulatory arrest. J Thorac Cardiovasc Surg. 2019;157:1360-8.e8.

6. Shah RM, Hirji SA, Kiehm S, Goel S, Yazdchi F, Bellavia A, et al. Debunking the July effect in cardiac surgery: a national analysis of more than 470,000 procedures. Ann Thorac Surg. 2019;108:929-34.

7. Lawton JS. Commentary: "Isn't cardiac surgery a team sport?" J Thorac Cardiovasc Surg. March 22, 2019 [Epub ahead of print]. 